\title{
The Ability of Pre-Service Primary Teachers to Produce Figural Patterns Based on Algebraic Formulas \\ Article History
}

Çiğdem Kılıç ${ }^{1}$

Received: 25 July 2016 Accepted: 15 March 2017 OnlineFirst: 17 July 2017

Abstract: In this study, the participants were asked to create figural patterns (figural representations) of two sequences, where the presentation is in the form of an algebraic formula. Those algebraic formulas were representing linear and quadratic (non-linear) patterns, in which pre-service primary teachers were asked to generate figural patterns based on those algebraic formulas. In total, 127 pre-service primary teachers participated in the study. The obtained data were analysed at two levels including both semantic and descriptive analyzes. The results of the study indicated that of 127 participants, 88 could generate a correct figural pattern of some kind for the given arithmetic sequence expressed via a linear function of $n$, while 72 were able to do so for the given nonlinear sequence expressed via a quadratic function of n. Follow-up individual interviews were conducted with 9 volunteer participants, reflecting a cross-section of types of responses, including some who were unable to respond and had some issues.

Keywords: Algebraic formula, figural pattern, linear pattern, non-linear pattern, representation types

DOI: $10.16949 /$ turkbilmat.329067

\section{Introduction}

Patterns are the heart and soul of mathematics (Zazkis \& Liljedahl, 2002). Pattern activities allow students to learn and engage in algebraic activity and make generalizations (Cathcart, Pothier, Vance \& Bezuk, 2003; Rivera \& Becker, 2007; Threlfall, 1999). Van de Walle (2004) indicated that identifying and extending patterns is an important process in algebraic thinking and patterns are tool for students' development of algebraic thinking (Lin, Yang \& Chen, 2004; Nathan \& Kim, 2007; Rivera, 2013; Steele, 2008; Van de Walle, 2004; Zazkis \& Liljedahl, 2002). Moreover, it is emphasised that reasoning on number patterns is important for developing algebraic thinking (Lin et al., 2004). Patterns can also contribute to the development of functional thinking (Souviney, 1994; Van de Walle, 2004; Warren \& Cooper, 2006), in terms of seeing relationships and making connections (Cathcart et al., 2003), problem solving (Bassarear, 2008; Cathcart et al., 2003; Reys, Suydam, Lindquist, \& Smith, 1998), counting (Bassarear, 2008; Frobisher \& Threlfall, 1999), and using number systems (Frobisher \& Threlfall, 1999) and arithmetical operations (Bassarear, 2008; Frobisher \& Threlfall, 1999). Cathcart et al. (2003) asserted that through the study of patterns, children can learn to see relationships and make connections, generalizations, and predictions about the world around them. Fox (2005) asserted that studying patterns is closely connected to mathematical content areas such as numbers, geometry, measurement, and data.

\footnotetext{
${ }^{1}$ Assoc. Prof. Dr., İstanbul Medeniyet University, Faculty of Education Sciences, Department of Mathematics and Science Education Sciences, cigdem.kilic@medeniyet.edu.tr
} 
There are many different representation forms including diagrams, graphs, tables, sketches, equations, and words (Bassarear, 2008). In the well-known classification of Lesh, Post \& Behr (1987), representations are pictures, manipulative models, oral language, written symbols, and real-world situations as shown in Figure 1.

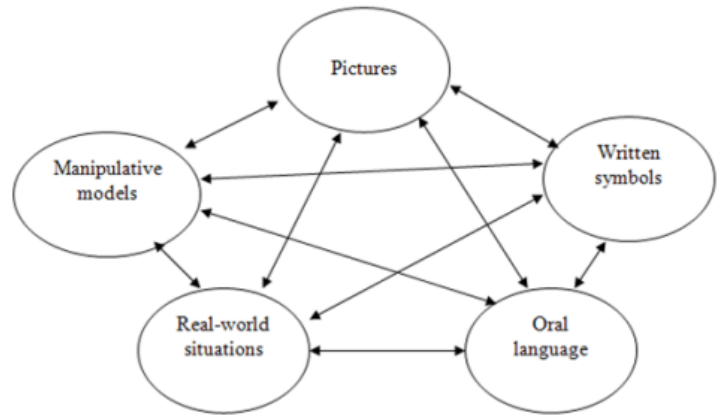

Figure 1. Representation types

Pictures, or diagrams-static figural models, can be internalised as images (Lesh, Post \& Behr, 1987), while manipulative models are objects that students can touch, move, and stack. Furthermore, as shown in the classification in Figure 1, representations are interrelated. Translation refers to the psychological process of going from one form of representation to another (e.g. going from an equation to a graph or vice versa; Janvier \& Bednarz, 1987). For instance, $y=4 x+1$ equation can be represented in a graph or a graph representing $4 x+1$ can be represented in an equation. Translations among representations assist mathematical learning and problem solving (Lesh, Post \& Behr, 1987) as well as help students understand mathematical concepts and relations more in depth. Steele (2008) indicated that "recognizing and understanding the relationship between different external representations of algebraic situations helps students identify and generalize patterns that lead toward understanding variables and functions" (p. 98).

As mentioned earlier, representation types are very important in pattern activities. Patterns can be represented in many ways (Van de Walle, 2004) such as physical materials (e.g. beads, coloured buttons, cubes), oral (e.g. the "do, mi, mi, do" pattern), numbers or symbolic rules (e.g. 2, 6, 12, 20 or $y=x^{2}+3 x$ ), and figures (geometric or not). Bassarear (2008) indicated that connecting geometric and numerical representations such as 1,10 , 100 , and 1000 by using base ten blocks is very important for understanding number systems. Indeed, forming connections among representations is a central goal of algebra instruction (Brenner et al., 1997). Thus, representation is very important in pattern activities such as generalization (Nathan \& Kim, 2007; Rivera \& Becker, 2008; Steele, 2008). Nathan and Kim (2007) indicated that different ways of presenting patterns (with graphs and words) affected the pattern generalization performance of students. Rivera and Becker (2008) found that generalizations involving linear figural patterns changed students' 
representational skills and fluency, that is, from being verbal (situated) to symbolic (formal). In that current study representation types in pattern activity was considered such as pictures (figures), manipulative models (physical materials), oral language, written symbols (numbers or symbolic rules) and real-world situations as indicated in the studies of Van de Walle (2004) and Lesh, Post and Behr (1987).

Teachers' knowledge and abilities are critical factors to improve students' mathematical learning, thus this current research' attempt to put effort on this issue is worth encouraging. In the literature, studies of patterns focus on the degree to which pre-service teachers understand pattern generalization. In particular, studies have determined the generalization strategies or process of creating numerical or figural patterns, representing linear and/or non-linear (quadratic) types. Zazkis and Liljedahl (2002), for example, focused on the capacity of pre-service elementary school teachers to generalize a repeating visual number pattern. In their study, participants were actively engaged in seeking a way to express their generalization. Their attempts to use algebraic notation, beyond simple labeling of elements and columns, often appeared unhelpful. Hallagan, Rule and Carlson (2009) asserted that although most pre-service teachers could solve a specific case, they had considerable difficulty determining an algebraic rule. Moreover, pre-service elementary school teachers encountered more difficulty with determining the algebraic generalization for items arranged in squares with additional single items as exemplified by $x^{2}+1$, than with multiple sets of items, as exemplified by $4 x$, while Chua and Hoyles (2010) asked pre-service teachers to generalize and represent figural patterns involving the quadratic rule symbolically. That study show that additive constructive generalisation was most commonly used (about 50\%), followed by reconstructive generalisation (about 30\%), and then non-additive generalisation (about 10\%). Tanışlı and Köse (2011) also examined preservice teachers' strategies for generalizing linear shape patterns. They found that while determining the rule of pattern and extending the linear shape pattern to next/ far step, some pre-service teachers adapted the numerical approach through which the visual and figural patterns that focus on only shape are conveyed into numerical pattern. While generalizing the patterns under the numerical approach, pre-service teachers applied recursive strategies in which only the relationship between the terms were examined and under the figural approach, they used the functional strategies which were both recursive in examining the relationship between the variables.In summary, while a number of studies have investigated pre-service teachers' knowledge of generalizing figural and/or numerical patterns (i.e. from figural or symbolic to symbolic representations), generating figural patterns based on algebraic formulas/ pattern general rules requiring translation between representations is under-researched. Considering ability of translation between representations is very important for problem solving, and assist mathematical learning including algebra, the present study bridges this gap in the literature by examining the ability of pre-service teachers to generate figural patterns based on algebraic formulas/ pattern general rules requiring translation between representations (i.e. from symbolic (algebraic formulas) to figural representations) which has potential to develop algebraic thinking of pre-service primary teachers. Furthermore, in that study it is expected to provide insights into the 
similarities and differences of pre-service teachers' abilities when generating both linear and non-linear figural patterns considering the algebraic formulas.

In this study, the following research questions are addressed:

- What kinds of figural patterns are generated by pre-service primary teachers based on linear and quadratic algebraic formulas?

- Are there any differences in the performances of participants when producing linear and quadratic figural patterns?

\section{Method}

Data were collected by using both quantitative and qualitative research methods.First of all, an algebraic formula (pattern general rule) task was carried out by all participants; and secondly nine volunteer participants representing different abilities participated in taskbased interviews. In this study, data triangulation was considered by supporting its quantitative findings by using qualitative research methods. In triangulation-based research design, "the researcher simultaneously collects both quantitative and qualitative data, compares the results, and then uses those findings to see whether they validate each other" (Fraenkel \& Wallen, 2005, p.443). The task-based interviews allowed the researcher to find out how figural patterns were generated or not and understand participants' cognition structures of generating process by analysing their responses.

That study took place in Turkey in a state university and also participants are prepared to teach mathematics in accordance with mathematics curriculum of the state primary schools in Turkey. Participants were selected by using a two-step sampling process. In the first step, 127 participants who took Mathematics Teaching Course I and attended Mathematics Teaching Course II participated in the study. In Mathematics Teaching Course I, participants were taught representation types (pictures, manipulative models, oral language, written symbols, and real-world situations) as indicated in the study of Lesh, Post \& Behr (1987), whole numbers, operations with numbers, properties and classification of geometric shapes, drawing and constructing geometric shapes and the Van Hiele model of geometric thought. In Mathematics Teaching Course II, participants were taught basic algebra, patterns, pattern types, and generalizing figural and number patterns in accordance with the primary school mathematics curriculum. Especially, in Mathematics Teaching Course II participants studied some mathematical activities related to patterns such as recognizing, describing, extending and creating a wide variety of patterns including both linear and non-linear patterns using different representations like pictures, manipulative models, oral language, written symbols, and real-world situations and all types of pattern generalization but did not study generating figural patterns based on algebraic formulas requiring translation between representation types due to the scope of the courses in teacher education programme and primary school mathematics curriculum. Moreover, prior to this study participants have done some teaching activities releated to scope of Mathematics Teaching Course I \& II courses. It was assumed that all participants already had basic 
knowledge of number, geometry and algebra. Moreover, participants in this study have not encountered pattern as a mathematical topic before their teacher education programme. Of these participants, 69 were women and 58 were men and their ages ranged between 20 and 21 years.

In the second step, maximum variation sampling (Miles \& Huberman, 1994) being one of the purposeful sampling techniques (Gay, Mills \& Airasian 2006) was used to choose participants for task-based interviews in order to understand in greater depth how they generated figural patterns related to both linear and non-linear pattern general rules. Nine volunteer participants for task-based interviews were selected. In that study the criterias for choosing participants were generating different figural patterns and having issues that emerged in the study. The real names of participants were kept confidential. Participants were thus coded $\mathrm{P}_{1}, \mathrm{P}_{2}$, and $\mathrm{P}_{3}$ (giving no answer), $\mathrm{P}_{4}, \mathrm{P}_{5}$, and $\mathrm{P}_{6}$ (producing no pattern), and $\mathrm{P}_{7}, \mathrm{P}_{8}$, and $\mathrm{P}_{9}$ (creating a correct pattern). The code "I" was used for the interviewer (the researcher).

127 participants were asked to generate figural patterns by considering an algebraic formula (general pattern rule) task consisting of one linear and one non-linear (quadratic) algebraic formula in a written form. Generating figural patterns based on an algebraic formula (general pattern rule) examined participants' translation performance between representation types (e.g. from symbolic to figural representations). The algebraic formula task is described following:

Task 1: Could you generate a figural pattern of five stages regarding the $4 n+1$ formula (pattern general rule?) and

Task 2: Could you generate a figural pattern of first five stages regarding the $\frac{n \cdot(n+1)}{2}$ formula (pattern general rule)?

If participants say yes for those two questions then they were asked to generate figural patterns in a form. If they say no for those questions, they were asked to write the reasons why they could not generate any figural patterns in a form $4 n+1$ linear and $\frac{n .(n+1)}{2}$ quadratic because of their nth terms expressed as $a n+b$ and $a n^{2}+b n+c$ algebraic formulas. Both tasks demand knowledge on pattern structures that grow according to the number of objects in each stage; thus, participants have the potential to generate several interesting figural patterns. The cognitive demands of the tasks in the study led the participants to create figural patterns considering algebraic formulas .To confirm the suitability of the task, the opinions of a relevant mathematics educator were considered. The educator indicated that the task used in this study was suitable for pre-service teachers.

In order to understand the conformity, validity, and reliability of the task-based interview questions, a pilot study was conducted with a pre-service teacher. Conducting a pilot study with one pre-service teacher was enough for interview questions because at the end of the pilot study it was realized that interview questions were comprehensible and 
illuminative; otherwise I would ask other pre-service teacher for pilot study. As a result of the pilot study, the questions were revised in order to prevent uncertainties as well as unexpected situations. In the actual interviews, participants were asked to read the task first and then to think aloud during the interview. The interview protocol was designed to help them explain how they were generating figural patterns based on the algebraic formulas. The questions used in the task-based interviews were open-ended in order to assess participants' thinking processes (Hunting, 1997). Interview questions included the following: Could you explain how you generated such a situation stage by stage? Do you think that the answer you generated is a pattern? Why? Could you explain? Do you think that the pattern you produced is in accordance with the algebraicformula (pattern general rule)? Why? Could you explain? Could you generate a different pattern based on the same algebraic formula? How? and Which type of formula did you find easier to produce pattern? Why? During the interviews participants were led to discover their errors through probes such as "Do you think the pattern that you created in accordance with the algebraic formulas? Could you explain?". The task-based interviews lasted for about 25-30 minutes. All interviews were recorded for transcription and follow-up analyses.

The data obtained from the algebraic formula (pattern general rule) task were analysed at two levels: (i) semantic analysis and (ii) descriptive analysis. In the semantic analysis, Table 1 and Table 2 have been utilized to analyze the responses of participants considering their responses. The figural patterns generated by participants were analyzed in accordance with the linear or non-linear formulas to assess their ability to generate figural patterns. The produced figural patterns were first listed and classified according to their semantic structures. Generated patterns or situations were then coded as linear or quadratic patterns and issues were noted. After the semantic analysis of the generated patterns, their frequencies and percentages were calculated. The descriptive analysis then provided descriptive information to offer an overall picture of the figural patterns generated by participants.

After the main data collection process, the interview transcripts were transcribed verbatim by the researcher. The interview data were analysed by using Miles and Huberman's (1994) data analysis model, which consists of three phases: data reduction, data display, and conclusion drawing/verification. In the data reduction phase, the researcher coded the data that were considered to be important concepts and patterns for the study. Content analysis was used for coding data. Raw data were coded and categorised to capture the relevant characteristics from the interview transcripts (Merriam, 1998). The generated figural patterns were analysed by using the Table 1 and Table 2 .

Interviews excerpts are given after these categories. The figural representations of the $4 n+1$ and $\frac{n \cdot(n+1)}{2}$ algebraic formulas were coded as types (Type 1, Type 2, etc.) placed in the literature to analyse the data obtained from the study effectively. Table 1 and Table 2 provide the pattern types for the $4 n+1$ and $\frac{n \cdot(n+1)}{2}$ in the literature. In the results section, besides those pattern types from the literature, some of the new pattern types created by 
participants for the linear and quadratic algebraic formulas (pattern general rules) are presented.

As seen in Table 1, the representation types of $4 n+1$ seem to differ in terms of arrangement. Geometric figures such as squares and circles are used to represent those types of patterns. Although the same geometric shapes are used for Types 1 and 2 (squares) and Types 4 and 5 (circles), the construction of those patterns differs because of the arrangement.

Table 1. Examples of figural representations (patterns) of the $4 n+1$ algebraic formula in the literature

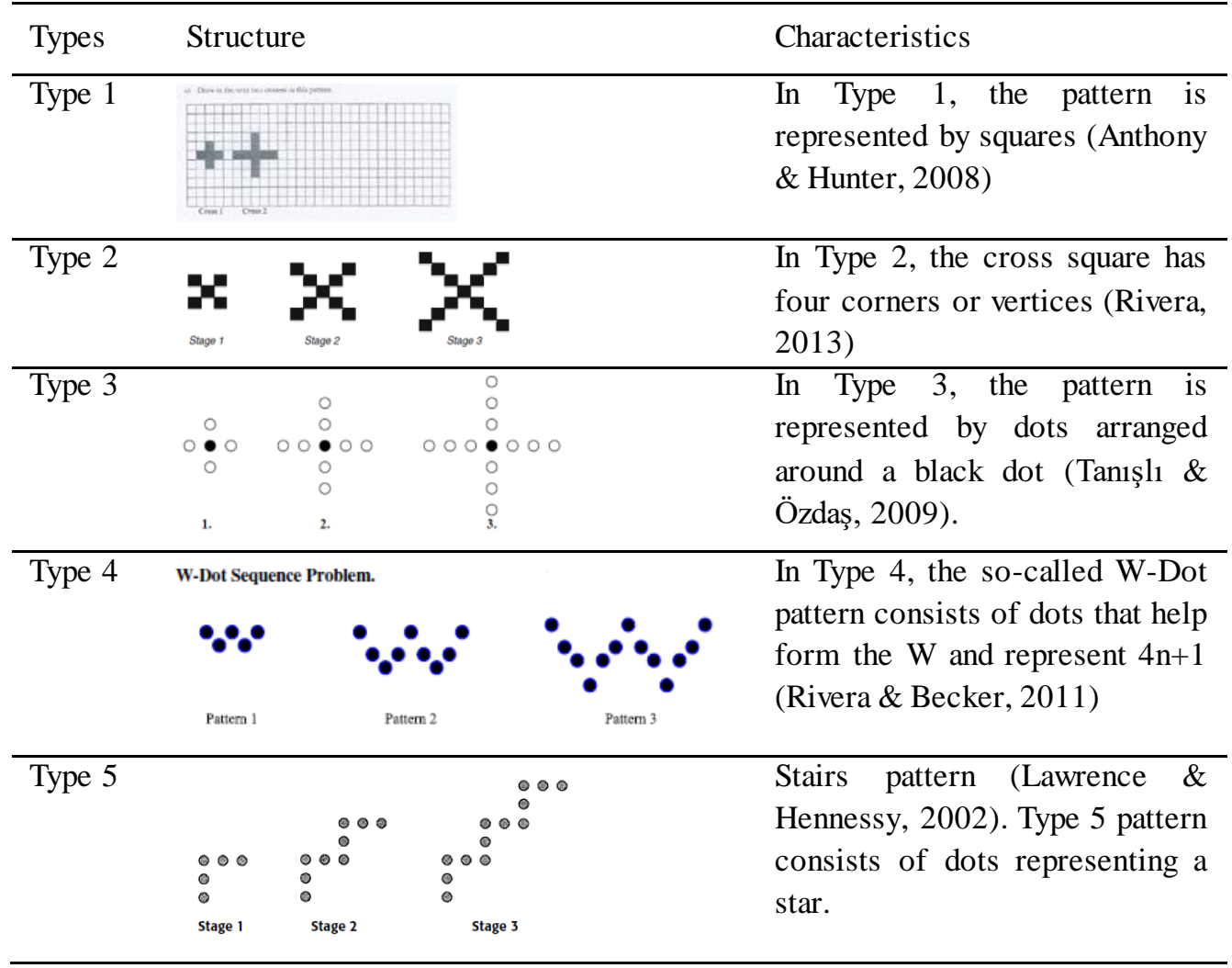


Table 2. Examples of figural representations (patterns) of the $\frac{n \cdot(n+1)}{2}$ algebraic formula in the literature

Types Structure

Type 1
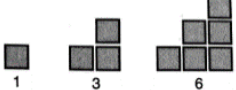

10

Type 2

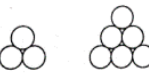

3

6

10

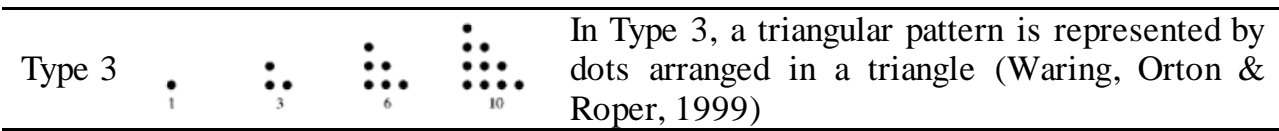

Type 4

10

15
Characteristics

In this pattern, squares are arranged like stairs (Bennett \& Nelson, 1998)

The Type 2 pattern is represented by circles (Souviney, 1994)

In Type 4, the triangular pattern consists of dots to help form a triangle (Blitzer, 2011)
Type 5

Type 6

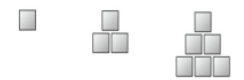

In Type 5, the triangular pattern consists of dots and lines (Miller, Heeren \& Hornsby, 2012)

This pattern is like a pyramid (Increasing patterns, 2009)

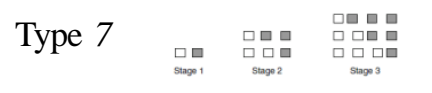

In Type 7, black shapes represent the rule (Rivera, 2013)

As seen in Table 2, although the figural pattern examples given for $\frac{n \cdot(n+1)}{2}$ formula represent the same algebraic formula, their structures have different arrangements and shapes (e.g. square, circle, line, dot). However, while, for instance, for Types 1 and 6 same geometric shapes are used, the construction of those patterns are different because of the arrangement.

In order to increase the reliability and validity of the study, the member checks technique was used, as suggested by Lincoln and Guba (1985). In the study the researcher asked for the opinion and assessment of one colleague who was blinded to the data and unbiased regarding the code list and research findings. In order to examine inter-ratter reliability and increase the reliability of the qualitative results, another colleague who has a mathematics education background independently classified the generated figural patterns. The formula of Miles and Huberman (1994) was used to calculate inter-rater reliability and 
this was determined to be $94 \%$ for Task 1 and $90 \%$ for Task 2 . The disagreements were about whether the responses are patterns or not.The pilot study also contributed to the validity and reliability of the pattern rule task and interview questions.

In that study all the participants were informed about the aim of the research and asked to attend task based interviews after the main data collection process at the beginning of the study. The participants who attended the task based interviews signed a consent form to show that they participated in the study voluntarily. The real name of the participants was not used and was kept confidential.

\section{Findings}

In particular, the first five stages of figural pattern regarding the $4 n+1$ formula are presented in Table 3 and performance on the $\frac{n \cdot(n+1)}{2}$ formula is presented in Table 4. All responses are given in these tables in accordance with their structures.

Table 3 presents the frequency and percentage of responses related to the linear algebraic formula (linear pattern general rule) as well as the types of patterns and issues encountered by participants. Altogether, 88 (69.29\%) participants could produce figural patterns and $39(30.70 \%)$ could not. As seen in Table 3, 14 different figural patterns were created by participants for the $4 \mathrm{n}+1$ formula (pattern general rule) during the study. In the study Type 1 created by $46(36.22 \%)$ participants, Type 2 by seven $(5.51 \%)$, and Type 3 by two $(1.57 \%)$. Those types were placed in the literature but other 11 pattern types were created by participants were different forms.

Table 3.Responses of participants related to the $4 \mathrm{n}+1$ algebraic formula ( $\mathrm{f}=$ Frequency, $\%=$ percentage, $\mathrm{N}=127$ )

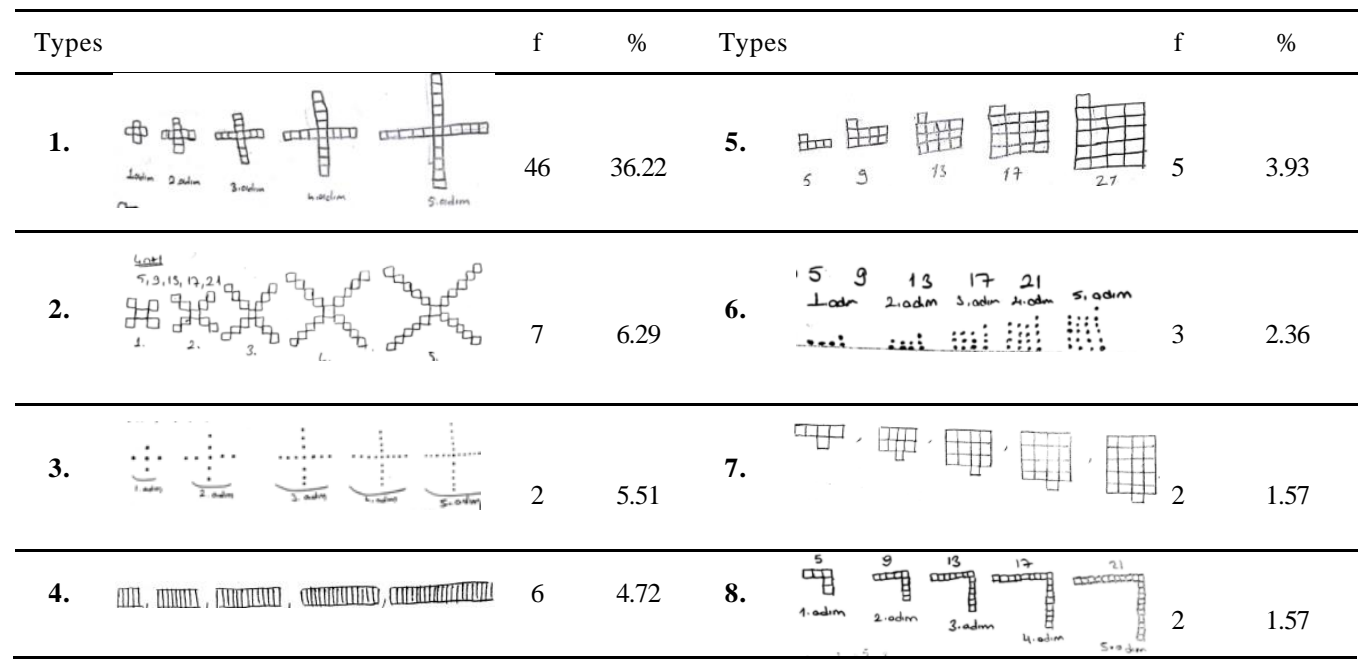


Table 3 continued

9.

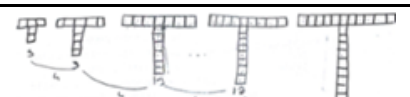

1.57

14.

0.78

10

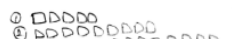

6
6

$2 \quad 1.57$

Correct pattern (total)

88

69.29

11.

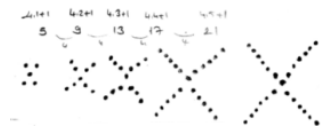

$2 \quad 1.57$

No answer

12

9.45

Not being a $4 n+1$ pattern

27

21.26

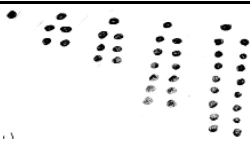

12.

$1 \quad 0.78$

Issues (total)

39

30.71

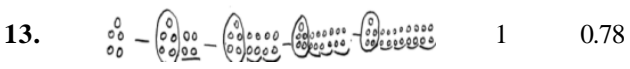

Types 1 and Type 9 represent an addition sign. Type 3,11 show a cross pattern, which might be thought of as consisting of a single element (be it a dot, circle, square or whatever) at the centre of 4 equal arms. It thus could be regarded as showing the structure of $4 n+1$ very clearly, including the fact that as $\mathrm{n}$ increases by 1 , the number of elements increases by 4 (since each arm increases by 1). Types 5, 6, 7 can be described as an array consisting of rows (or columns) of 4 elements (dots, or squares, etc) with an extra, single, element tacked on somewhere. This again shows the ' +4 ' growing nature of the relation very clearly, although one might argue not as saliently as the 4 -armed cross types. In Type 10 each arrangement in the pattern consists simply of a single row of elements. In the case of Type 10 , these arrangements are placed underneath each other, so that it is fairly easy to discern that successive arrangements increase by 4 elements each time. In Type 4 , the successive rows of elements are placed next to each other, so it is far less obvious that successive elements increase by the same amount, and that this amount is 4 . Type 2 represents $\mathrm{T}$ model. Types 12,13,14 consist of two rows and Type 8 can be described as inverted L. Examples of the figural patterns created and interview excerpts are given below: 


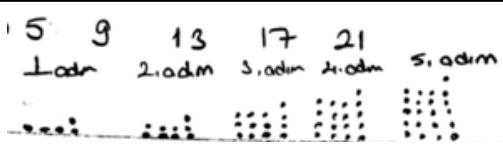

Figure 2. Drawing example

I: In the first task, I asked you to generate a figural pattern based on the formula (rule). You created this. Could you explain how you generated this pattern stage by stage?

$\mathrm{P}_{1}$ : First of all, I focused on the formula-rule. It is related to series. I put one number into the $4 n+1$ formula. I then found the first, second, third, fourth, and fifth terms of the pattern. I created a number pattern and then generated a figural pattern. I created the first stage of the figural pattern with five dots and then used this to generate the remaining stages of the pattern, adding four in every stage. I focused on four because the pattern is increasing by four in every stage. I thought using dots would be easy for me. I could have used other geometric forms such as triangles or squares in a systematic way, but using dots was easy for me so I preferred to use them to generate this figural pattern.

I: Very good. Do you think that this is a pattern or not? Why? Could you explain?

$\mathrm{P}_{1}$ : Yes, it is a pattern. There is a relation and those figures are made of dots set out in arrays that grow by a constant number. There is an order.

I: Do you think that the pattern you produced is in accordance with the formula- rule? Why? $\mathrm{P}_{1}$ : Yes it is. Because the terms of the pattern are growing in every stage s. I started with one not zero. If I had started with zero instead of one, how would I show a figural pattern for zero?

$\mathrm{P}_{1}$ generated a correct figural pattern by considering the formula (general rule) and during the interview mentioned that she could have created another example by using either geometric or non-geometric shapes based on the same formula.

The pattern produced by participant $\mathrm{P}_{2}$ is shown as below:

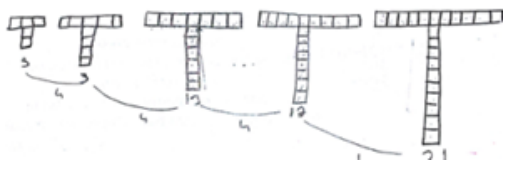

Figure 3. Drawing example

$\mathrm{P}_{2}$ mentioned that he first gave some values for $\mathrm{n}$ and then found the 5-9-13-17 number pattern to generate the figural pattern. Moreover, he indicated that it was a growing pattern because of the systematic structures and that he could have generated another figural pattern for $4 \mathrm{n}+1$ formula by using other geometric shapes such as circles, triangles, or dots. $\mathrm{P}_{2}$ stated that he could also have generated a pattern representing a T model or another pattern based on the same rule. 
Participant $\mathrm{P}_{3}$ created the figural pattern is below:
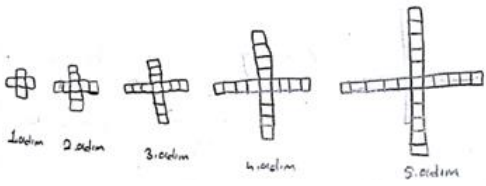

Figure 4. Drawing example

During the interview, participant $\mathrm{P}_{3}$ declared that he generated a number pattern (5-9-1317-21) and then a figural pattern (Type 1) based on it. He explained that he fixed the first stage of the figural pattern and added four to each of the former stages. Furthermore, he declared that he could have generated many more patterns by using either geometric or nongeometric shapes.

Some participants encountered issues when generating figural patterns following the $4 n+1$ algebraic formula. Eleven participants (8.66\%) failed to provide a response and 27 $(21.25 \%)$ did not offer a correct figural pattern following the $4 n+1$ formula. $\mathrm{P}_{7}$ and $\mathrm{P}_{9}$ declared that they could only generate a number pattern and did not create figures. When the interviewer asked why they did not create any figures, they declared that it was the first time they had learnt patterns on the course and had not met the topic before. Moreover, they said that both types of generating figural pattern activities were very difficult for them. Participant P8, who also did not generate any figural patterns, indicated that she produced a 1-5-21-85-341 number pattern and that those numbers represented the formula. However, she provided an incorrect number pattern for the formula. Moreover, even during the taskbased interview, she did not realise that those numbers do not represent the $4 n+1$ formula. Another non-pattern was produced by participant P4:

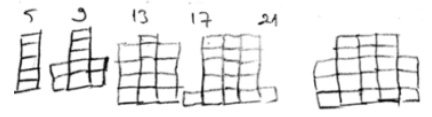

Figure 5. Drawing example

During the interview, participant $\mathrm{P}_{4}$ mentioned that he could not generate that figures consciously. He said that he created a number pattern first and then the figural pattern by considering the numbers in every stage. In addition, he mentioned that it should be a pattern because the numbers and shapes align. Furthermore, he stated that he did not know how to create another figural pattern but could have created one by using other shapes in the same way and also he did not realise the non-systematic situation. Another example of an incorrect figural pattern produced by participant $\mathrm{P}_{5}$ and interview excerpt is below: 

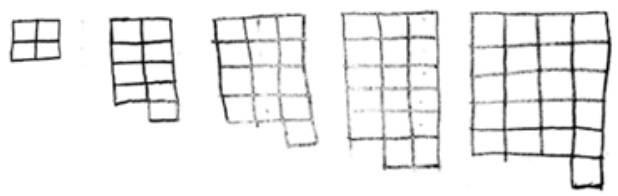

Figure 6. Drawing example

I: In that task, I asked you to generate a figural pattern based on the formula. You created this. Could you explain how you generated this pattern stage by stage?

$\mathrm{P}_{5}$ : I produced 5-9-13-17-21 number pattern based on the formula and tried to create figures based on that number pattern.

Participant $\mathrm{P}_{5}$ created a 5-9-13-17-21 pattern in accordance with the formula (general rule) and created figures according to these numbers. $\mathrm{P}_{5}$ 's pattern perception is thus very limited as he did not generate a correct figural pattern. Participant P6 also generated a nonpattern by using circles, that is not considering the array and only focusing on the number pattern. Moreover, she declared that she circled all the shapes in every stage. The example as below;

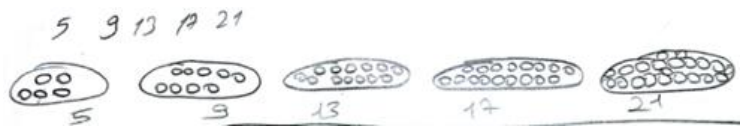

Figure 7. Drawing example

Table 4. Responses of participants related to the $\frac{n \cdot(n+1)}{2}$ algebraic formula ( $\mathrm{f}=$ Frequency, $\%=$ percentage, $\mathrm{N}=127$ )

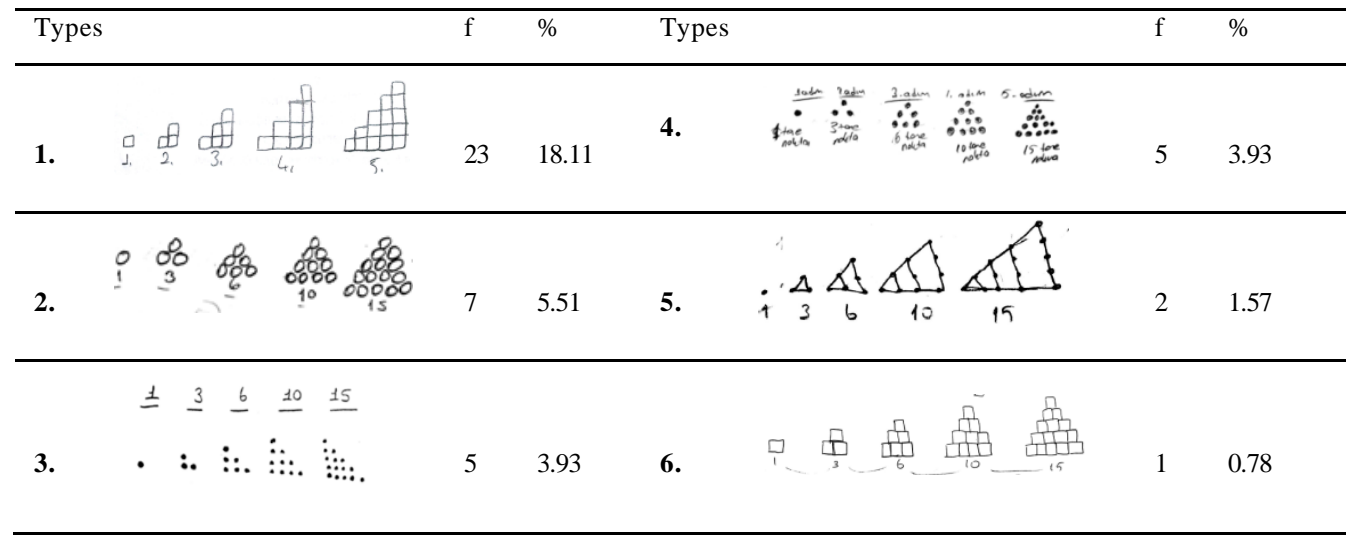


Table 4 continued

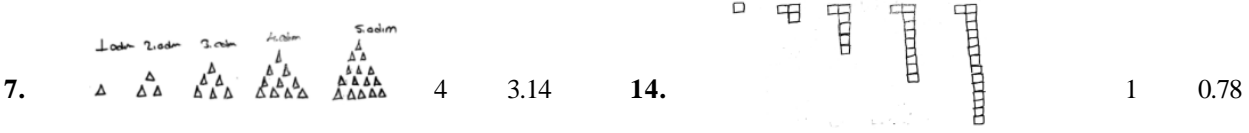

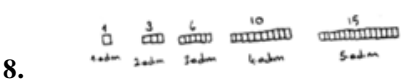

$13 \quad 10.23$

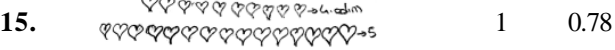
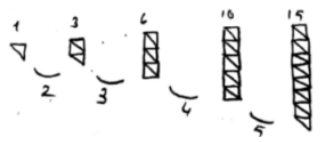

$1 \quad 0.78$

16.

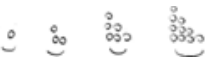

has

4

3.14

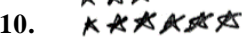

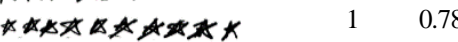

17.

$\Delta, \Delta, \Delta \Delta, \Delta \Delta \Delta$

$1 \quad 0.78$

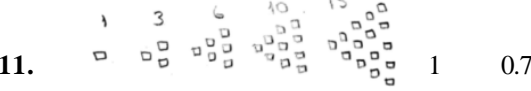

Correct pattern (total)

$72 \quad 56.69$

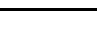

12.

(1) (1) (1)

0.78

No answer

Not being a $\frac{n \cdot(n+1)}{2}$ pattern

Issues (total)
$15 \quad 11.81$

$40 \quad 31.49$

13. 0 o

13. 10. 10.78

Table 4 presents the frequency and percentage of responses related to the algebraic formula (quadratic pattern general rule) as well as the types of patterns and issues encountered by participants. For the $\frac{n \cdot(n+1)}{2}$ pattern, Types $1,3,16$ seem structurally different as it shows the triangular configuration as half of a rectangular one of sides $n$ by $n+1$. Types $8,9,12,17$ represent a linear model. Types $2,4,6,7$ can be described as pyramid model. In those types, one being first term of pattern is at the top and a structure increasing downward. Type 5 can be described as the triangular pattern consists of dots and lines. Structure of Type 13 represents the total of numbers from 1 to $n$ such as $1,1+2,1+2+3$, Type 14 can be described as inverted L except first term of pattern. Types 10 and 15 do not expand side by side. Type 11 represents like a triangle.

As shown in Table 4, 72 (56.69\%) participants could produce figural patterns and 55 $(43.30 \%)$ could not. During this activity, 17 different figural patterns were generated by participants, with Type 1 created by 23 (18.11\%), Type 2 by seven (5.51\%), and Type 3,4 
by five (3.93\%), Type 5 by two (1.57\%) and Type 6 by one (0.78). Besides those figural patterns participants created different figural patterns. The figural pattern created by participant $\mathrm{P} 1$ is shown below:

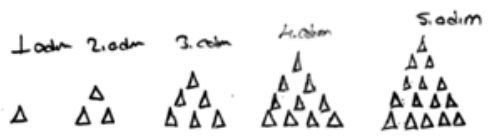

Figure 8. Drawing example

During the interview, participant $\mathrm{P}_{1}$ mentioned that she generated the number pattern 1-36-10-15 and used triangles to convert those numbers into a figural pattern. She indicated that it was a pattern because it was an array. She declared that generating a figural pattern for $4 n+1$ was easier than it was for $\frac{n \cdot(n+1)}{2}$ because the second task has more arithmetic operations than the first (i.e. multiplication, addition, and division). $\mathrm{P}_{1}$ generated a correct figural pattern but not one that can be seen in the literature. She used triangles to re present a triangular pattern. Another example belongs to participant $\mathrm{P}_{2}$ :

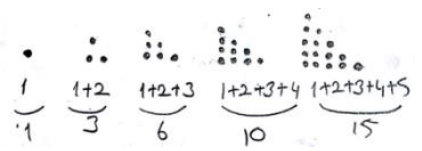

Figure 9. Drawing example

$\mathrm{P}_{2}$ mentioned that he found the 1-3-6-10-15 number pattern first by considering the accrual between two terms. He declared that he preferred to use dots because the numbers are big and while drawing figures he could make a mistake. Furthermore, he realised another pattern (i.e. 2-3-4-5 etc) between the 1,3,6,10 numbers in number pattern. He said that he could have generated another figural pattern by using other shapes and indicated that the $4 n+1$ task was much easier than the $\frac{n \cdot(n+1)}{2}$ one. $P_{2}$ also generated a correct figural pattern for $\frac{n \cdot(n+1)}{2}$ (i.e. a Type 3 pattern). Furthermore, he declared that he could have generated another figural pattern for the same formula by using different shapes. Another example comes from participant $\mathrm{P}_{3}$ :

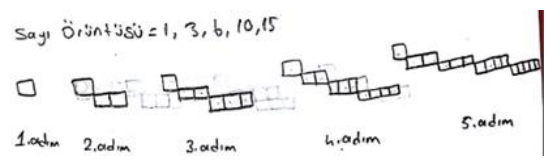

Figure 10. Drawing example

When the interviewer asked this participant to explain the process stage by stage, he declared that he generated the number pattern 1-3-6-10-15 as in the first task and then created the first term of the figural pattern. After, he generated other terms based on the 
number pattern and the first fixed term of the pattern in accordance with the formula. By using different types of figures, he could have generated other patterns. He found the first task much easier than the second task.

In terms of issues, $15(11.81 \%)$ participants provided no response and $40(31.49 \%)$ did not provide a correct figural pattern following the $\frac{n \cdot(n+1)}{2}$ algebraic formula (pattern general rule). Participants $\mathrm{P}_{7}$ and $\mathrm{P}_{9}$ indicated that they could not imagine any figures for either Task 1 but found task 1 easier than Task 2. Participant $\mathrm{P}_{8}$ mentioned that she found the 2-36-21-231 number pattern for the $\frac{n \cdot(n+1)}{2}$ formula and indicated that all these numbers represent the formula. Participant P8 neither found a correct number pattern for the $\frac{n \cdot(n+1)}{2}$ formula nor generated any patterns. During the interview she was not aware that she had made a mistake. Another non-pattern was produced by participant $\mathrm{P}_{4}$ is below:

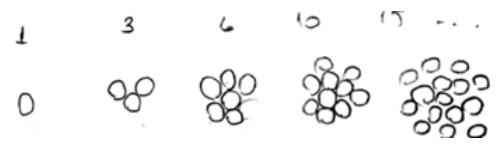

Figure 11. Drawing example

She mentioned that she created number patterns and considered the first stage of the figural situation as a magnet and the other circles surrounded it. Moreover, she did not realise that her figures were not constructed in a figural pattern. She mentioned that her figure had a sub-pattern and had more difficulty in the $\frac{n \cdot(n+1)}{2}$ task compared with the $4 n+1$ one because of the numbers in the pattern. Participant P4 used circles to create a figural pattern for $\frac{n \cdot(n+1)}{2}$ but did not create a correct figural pattern. She could, however, write number patterns for $\frac{n \cdot(n+1)}{2}$ correctly. Another example of an incorrect figural pattern was provided by participant $\mathrm{P}_{5}$ is below:

$$
\begin{aligned}
& 1-3-6-10-15-?
\end{aligned}
$$

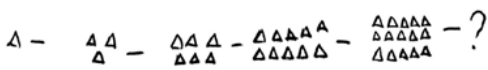

Figure 12. Drawing example

$\mathrm{P}_{5}$ indicated that she generated her figural pattern based on the number pattern and that it was a pattern because of its consistent numbers. She said she could have extended that figure by creating a new one and found $4 n+1$ easier than the second task. $P_{5}$ could not create a correct pattern. She generated a number pattern correctly but did not relate that number pattern to the figure. When creating a figural pattern, she used squares. Hence, she focused only on the number pattern and was not aware that the shapes she used to produce the figural pattern were not in order. Those figures were not made of squares set out in arrays. 


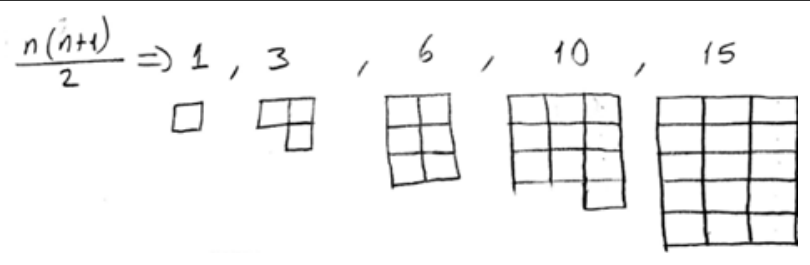

Figure 13. Drawing example

Participant $\mathrm{P}_{6}$ also created a non-figural pattern as shown in Figure 14. During the interview, she mentioned that she focused on the number pattern before creating the figural pattern and tried to follow it when generating the figural pattern for the $\frac{n \cdot(n+1)}{2}$ formula. As seen from the example, she too focused only on a number pattern and was not aware that the shapes used were not in order.

\section{Discussion, conclusion and suggestions}

In order to develop students' knowledge of patterns, it is important to educate preservice teachers well-equipped. In the literature, as in the current research, many pattern studies have focused on how pre-service teachers generalize either figural or/and number patterns (Chua \& Hoyles, 2010; Hallagan et al., 2009; Rivera \& Becker, 2007; Tanışlı \& Köse, 2011; Zazkis \& Liljedahl, 2002) requiring translation ability representation types (i.e. translation from symbolic or figural (number or figural pattern) to symbolic representations (algebraic formula), whereas studies of translation ability between representation types (i.e. translation from symbolic (algebraic formula) to figural representations) which have potential to indicate pre-service teachers' algebraic thinking are scarce. Steele (2008) indicated that recognising and understanding the relationship between different external representations of algebraic situations help identify and generalize patterns and linking representations is thus very important for algebraic instruction (Brenner et al., 1997), and generalizing patterns (Steele, 2008). Therefore, this study examined the ability of preservice primary teachers to generate figural patterns based on algebraic formulas for both linear and non-linear sequences.

The data obtained from the current study indicated that different types of figural patterns were generated by participants according to both algebraic formulas. In the study preservice primary teachers generated different types of figural patterns that followed the linear and non-linear algebraic formulas (pattern general rules) using different figures being either geometric or non-geometric forms. They could work from the formula to a possible figure to create different visual representations and created number patterns before generating figural pattern. Some of the figural patterns created by participants used geometric shapes predominantly during the generating activity for both the $4 n+1$ and the $\frac{n \cdot(n+1)}{2}$ formulas. Furthermore, the findings of this study indicated that pre-service primary teachers were more successful at creating figural patterns according to the linear formula (linear pattern 
general rule) compared with the non-linear (quadratic) formula (non-linear pattern general rule). During the interviews, participants also mentioned that finding a figural pattern for $4 n+1$ algebraic formula was easier than for $\frac{n \cdot(n+1)}{2}$. The structures of the algebraic formulas may the most important cognitive obstacle. As emerged in Hallagan et al.'s (2009) study of elementary school pre-service teachers, who encountered more difficulties determining the algebraic generalization for quadratic patterns than they did for linear patterns. Similarly, Steele (2008) also found that it is important to use multiple representations and link them in pattern activities. In that study, 88 of the participants for linear and 72 of them for nonlinear formulas were able to make translations from (i.e. they linked symbolic representations to figural ones) algebraic formulas to figural patterns. Those participants could interpret the symbol-configurations in the presented tasks to could create figural representation for the formulas. Moreover, some new figural patterns representing the $4 n+1$ and $\frac{n .(n+1)}{2}$ algebraic formulas (pattern general rules) emerged in the present study. Most of these figural patterns were created by using geometric structures such as rectangles and squares; thus, performance here can be related to their geometry ability. Furthermore, not only geometric shapes but also non-geometric shapes such as hearts and stars were used for creating figural patterns. The analysis of figural pattern types brings out the importance of spatial reasoning and spatial structuring and how the figural patterns are linked to participants' visualisation.

38 participants for $4 n+1$ algebraic formula and 55 participants for $\frac{n_{\cdot(n+1)}}{2}$ could not create figural patterns based on the formulas and they produced irrelevant figures (both geometric and non-geometric) that related to neither the $4 n+1$ nor the $\frac{n_{(}(n+1)}{2}$ algebraic formulas. Fox (2005) found that patterns are closely connected to mathematical content areas such as geometry, which can be affect participant performance. Furthermore, it can be concluded that pre-service teachers struggle to select and construct an appropriate representation when generating figural patterns. 27 of the participants for linear formula and 55 of the participants for non-linear formula in this study could not translate from algebraic formulas to figural representations. The scope of the courses in teacher education may affect participants' ability of producing figural patterns based on algebraic formulas. In the method courses participants did not study generating figural patterns based on the algebraic formulas because of the scope of the primary school mathematics curriculum and method courses of teacher education programme. For that reason, teacher education programmes should include courses including the activities such as generating figural patterns following algebraic formulas in order to develop pre-service teachers' algebraic thinking.

During the interviews, participants could define patterns but their perceptions of patterns were not at the desired level. As emerged in the study by Houssart (2000), some teachers had a wider and more sophisticated view of patterns. For that reason, pattern activities that can develop the perceptions of pre-service teachers should be designed for teacher training courses. In addition, generating figural patterns is related to participants' ability to visualise 
pictures and shapes and spatial reasoning thus this may have affected their performance. Moreover, other variables related to learners' performance such as learning style and mathematical thinking style might have influenced their creating figural patterns. For that reason, in order to understand participant performance more in depth, correlation studies should be conducted.

In the current study, pre-service teachers' translation ability from symbolic representations to figural ones was investigated. However, in the future, different representation types of patterns such as physical materials, oral, numbers, or symbolic rules could be given participants and then can be asked to create patterns such as from physical materials representation to symbolic representation or other representations. As a result, the translation ability of participants could develop by using different types of representations such as words, symbols, and real-world objects. Moreover, generating patterns based on algebraic formulas has the potential to improve the creativity of participants when other types of growing pattern general rules are given in order to understand their creativity levels in pattern generating. The strategies that participants use while generating figural patterns should also be investigated further (e.g. by using a figural pattern pathway) to understand their performance in that subject. In the future studies cognitive obstacles associated with creating figural patterns of the given pattern rules can be investigated in detail. Furthermore, for future studies such research can be investigated "How does the ability of pre-service primary teachers to produce figural patterns based on algebraic formulas improve pattern generalization? Is there any coherence between those who succeed in generalization or in algebraic thinking, and those who successfully generate a figural pattern for a algebraic formulas (pattern general rule)?.

\section{References}

Anthony, G., \& Hunter, J. (2008). Developing algebraic generalisation strategies. In O. Figueras, J. L. Cortina, S. Alatorre, T. Rojano \& A. Sepulveda (Eds.), Proceedings of the Joint Meeting of PME 32 and PME-NA XXX. Cinvestav, Mexico (Vol. 2, pp. 65 72). Mexico: Cinvestav UMSNH.

Bassarear, T. (2008). Mathematics for elementary school teachers. (5th ed.). CA: Brooks/Cole.

Bennett, A. B., \& Nelson, T. L. (1998). Mathematics for elementary teachers: An activity approach. (4th ed.). Boston, MA: Mc Graw Hill.

Blitzer, R. (2011). Thinking mathematically. (5th ed.). London, England: Pearson Education Limited.

Brenner, M. E., Mayer, R. E., Moseley, B., Brar, T., Durán, R. , S., Reed, B., \& Webb, D. (1997). Learning by understanding: The role of multiple representations in learning algebra. American Educational Research Journal, 34(4), 663-689. 
Cathcart, W. G., Pothier, Y. M., Vance, J. H., \& Bezuk, N. S. (2003). Learning mathematics in elementary and middle schools. (3rd ed.). Englewood Cliffs, N.J.: Merrill/Prentice Hall.

Chua, L. B., \& Hoyles, C. (2010). Generalisation and perceptual agility: how did teachers fare in a quadratic generalising problem? Research in Mathematics Education, 12(1), 71-72.

Fraenkel, J., R., \& Wallen, N. E. (2005). How to design and evaluate research in education. (6th ed.). New York, NY: Mc Graw Hill.

Fox, J. (2005). Child-initiated mathematical patterning in the pre-compulsory years. In $\mathrm{H}$. L. Chick \& J. L. Vincent (Eds.), Proceedings of the 29th Conference of the International Group for the Psychology of Mathematics Education. (Vol. 2, pp. 313320). Melbourne, Australia: University of Melbourne.

Frobisher, L., \& Threlfall, J. (1999). Teaching and assessing patterns in number in the primary years. In A. Orton (Ed.), Pattern in the teaching and learning of mathematics (pp. 84-103). London, England: Cassell.

Gay, L. R., Mills, G. E., \& Airasian, P. (2006). Educational research: Competencies for analysis and applications (8th ed.). Upper Saddle River, NJ: Pearson Prentice Hall.

Hallagan, J. E., Rule, A. C., \& Carlson, L. F. (2009). Elementary school pre-service teachers' understandings of algebraic generalizations. The Montana Mathematics Enthusiast, 6(1\&2), 201- 206.

Houssart, J. (2000). Perceptions of mathematical pattern amongst primary teachers. Educational Studies, 26 (4), 489-502.

Hunting, R. P. (1997). Clinical interview methods in mathematics education research and practice. Journal of Mathematical Behavior, 16(2), 145-165.

Increasing patterns (2009, February 15). Retrieved from http://www.learnalberta.ca/content/mepg2/html/pg2_increasingpatterns/index.html

Janvier, B. D., \& Bednarz, N. (1987). Pedagogical considerations concerning the problem of representation. In C. Janvier (Ed), Problems of representation in the teaching and learning of mathematics (pp. 67-72). New Jersey, NJ: Lawrence Erlbaum Associates.

Lawrence A., \& Hennessy, C. (2002). Lessons for algebraic thinking: Grades 6-8. CA: Math Solutions Publications.

Lesh, R., Post, T., \& Behr, M. (1987). Representations and translations among representations in mathematics learning and problem solving. In C. Janvier (Ed.), Problems of representation in the teaching and learning of mathematics (pp. 33-40). Hillsdale, NJ: Lawrence Erlbaum Associates.

Lincoln, Y. S., \& Guba, E. G. (1985). Naturalistic inquiry. Newbury Park, CA: Sage Publication.

Lin, F-L., Yang, K-L., \& Chen, C-Y. (2004). The features and relationships of reasoning, proving and understanding proof in number patterns. International Journal of Science and Mathematics Education, 2, 227-256.

Merriam, S. B. (1998). Qualitative research and case study applications in education. (1st ed.). San Francisco, SF: Jossey-Bass. 
Miller, C. D., Heeren, V. E., \& Hornsby, J. (2012). Mathematical ideas. (12th ed.). Boston, MA: Pearson Education.

Miles, M. B., \& Huberman, A. M. (1994). An expanded sourcebook qualitative data analysis (2nd ed.). Thousand Oaks, CA: Sage.

Nathan, M. J., \& Kim, S. (2007). Pattern generalization with graphs and words: A cross sectional and longitudinal analysis of middle school students' representational fluency. Mathematical Thinking and Learning, 9(3), 193-219.

Reys, R. E., Suydam, M. N., Lindquist, M. M., \& Smith, N. L. (1998). Helping children learn mathematics. (5th ed.). Boston, MA: Allyn\&Bacon.

Rivera, F. D., \& Becker, J. R. (2007). Abduction-induction (generalization) processes of elementary majors on figural patterns in algebra. Journal of Mathematical Behavior, 26(2), 140-155.

Rivera, F. D., \& Becker, J. R. (2008). Middle school children's cognitive perceptions of constructive and deconstructive generalizations involving linear figural patterns. ZDM Mathematics Education, 40, 65-82.

Rivera, F. D., \& Becker, J. R. (2011). Formation of pattern generalization involving linear figural patterns among middle school students: Results of a three-year study. In J. Cai \& E. Knuth (Eds.), Early algebraization: A global dialogue from multiple perspectives . Advances in mathematics education (pp.323-366). Berlin Heidelberg, Germany: Springer-Verlag.

Rivera, F. (2013). Teaching and learning patterns in school mathematics. New York, NY: Springer.

Souviney, R. J. (1994). Learning to teach mathematics (2nd ed.). New York, NY: Merrill. Steele, D. (2008). Seventh-grade students' representations for pictorial growth and change problems. ZDM Mathematics Education, 40, 97-110.

Tanışlı, D. \& Özdaş, A. (2009). İlköğretim Beşinci Sınıf Öğrencilerinin Örüntüleri Genellemede Kullandıkları Stratejiler. KUYEB, 1455-1497.

Tanışl1, D., \& Köse, N. (2011). Generalization strategies about linear figural patterns: Effect of figural and numerical clues. Education and Science, 36(160), 184-198.

Threlfall, J. (1999). Repeating patterns in the early primary years. In A. Orton (Ed.), Pattern in the teaching and learning of mathematics (pp.18-30). NY: Casse.

Van de Walle J. A. (2004). Elementary and middle school mathematics. Teaching developmentally. (5th ed.). Boston, MA: Allyn \&Bacon.

Waring, S., Orton, A., \& Roper, T. (1999). Pattern and proof. In A. Orton (Ed.), Pattern in the teaching and learning of mathematics (pp.18-30). London, England: Cassel.

Warren, E., \& Cooper, T. (2006). Using repeating patterns to explore functional thinking. Australian Primary Mathematics Classroom, 11(1), 9-14.

Zazkis, R., \& Liljedahl, P. (2002). Generalization of patterns: The tension between algebraic thinking and algebraic notation. Educational Studies in Mathematics, 49, 379 -402 . 


\section{Citation Information}

Kılıç, Ç. (2017). The ability of pre-service primary teachers to produce figural patterns based on algebraic formulas. Turkish Journal of Computer and Mathematics Education, 8(2), 261-283. 


\section{This page intentionally left blank.}

